\title{
Low-field magnetic resonance imaging or combined ultrasonography and anti-cyclic citrullinated peptide antibody improve correct classification of individuals as established rheumatoid arthritis: results of a population-based, cross-sectional study
}

Jens K Pedersen ${ }^{1,2^{*}}$, Tove Lorenzen ${ }^{1}$, Bo Ejbjerg ${ }^{3}$, Marcin Szkudlarek ${ }^{4}$, Anne Voss², Mikkel Østergaard ${ }^{5,6}$, Anders J Svendsen ${ }^{7}$, Lis S Andersen ${ }^{1}$ and Kim Hørslev-Petersen ${ }^{1,8}$

\begin{abstract}
Background: The aim of the present study was to evaluate the accuracy of two approaches using magnetic resonance imaging (MRI) or combined ultrasonography (US) and anti-cyclic citrullinated peptide antibody (ACPA) for diagnosis and classification of individuals with established rheumatoid arthritis (RA).

Methods: In 53 individuals from a population-based, cross-sectional study, historic fulfilment of the American College of Rheumatology (ACR) 1987 criteria ("classification") or RA diagnosed by a rheumatologist ("diagnosis") were used as standard references. The sensitivity, specificity and Area under Curve for Receiver Operating Characteristics curves (ROC-area: (sensitivity + specificity)/2) were calculated for "current fulfilment of the ACR 1987 criteria" (list format), "adapted ACR 1987 criteria" (list format, substituting IgM rheumatoid factor with ACPA and clinical joint swelling and erosions on radiography with synovitis and erosions detected by US on a semi-quantitative scale), and RA MRI scoring System (RAMRIS) scores on low-field MRI in the unilateral hand.
\end{abstract}

Results: For the ACR 1987 criteria the ROC-area was 75\% (sensitivity/specificity= 50\%/100\%) (with "classification" as standard reference) and 69\% (44\%/94\%) (with "diagnosis" as standard reference), while for the adapted ACR 1987 criteria it was 86\% (75\%/97\%) (classification) and 82\% (72\%/91\%) (diagnosis). For RAMRIS synovitis score in metacarpophalangeal (MCP) joints only (cut-off $\geq 5$ ), the ROC-area (sensitivity/specificity) was $78 \%$ (62\%/94\%) (classification) and $85 \%$ (69\%/100\%) (diagnosis), while for the total synovitis score of MCP joints plus wrist (cut-off $\geq 10$ ) it was $78 \%$ (62\%/94\%) (both classification and diagnosis).

Conclusions: Compared with the ACR 1987 criteria, low-field MRI alone or adapted criteria incorporating US and ACPA increased the correct classification and diagnosis of RA.

Keywords: Sensitivity and specificity, Ultrasonography, Magnetic resonance imaging, Rheumatoid arthritis, Epidemiology

\footnotetext{
* Correspondence: jensk@dadlnet.dk

${ }^{1}$ King Christian 10th Hospital for Rheumatic Diseases, South Jutland Hospital,

Toldbodgade 3, 6300 Graasten, Denmark

${ }^{2}$ Department of Rheumatology, Odense University Hospital, Odense,

Denmark

Full list of author information is available at the end of the article
} 


\section{Background}

Rheumatoid arthritis (RA) is an autoimmune and often incapacitating inflammatory disease primarily affecting synovial joints. The treatment possibilities for patients with RA have improved recently with the emergence of several new disease-modifying antirheumatic drugs (DMARDs) and a focus on early intervention and tight inflammatory control [1]. Over time, a decrease in the numbers of swollen and tender joints, joint damage, disease activity, disability [2,3], and rates for most types of interventions of orthopaedic surgery have also been observed [4-6].

As a consequence, however, it may be increasingly difficult to ascertain individuals with RA in cross-sectional studies aiming to estimate disease occurrence or to verify RA in patients with established disease in clinical settings. In this situation sensitive imaging techniques and specific second generation anti-cyclic citrullinated peptide antibody (ACPA) [7,8] may perhaps provide relevant information.

In patients with arthritis, grey-scale (GS) ultrasonography (US) is more sensitive than clinical examination for detecting synovitis $[9,10]$ and more sensitive than conventional radiography for detecting bone erosions $[10,11]$. Power Doppler (PD) has been introduced for the assessment of synovitis and may provide additional information $[12,13]$.

There is growing evidence on the performance of lowfield, dedicated extremity magnetic resonance imaging (MRI) units for detecting joint inflammation and damage in RA. Low-field MRI is more sensitive than conventional radiography for detecting bone erosions [14] and with high-field MRI as standard reference the sensitivity and specificity for detecting erosions and synovitis is high [15]. In the detection of bone marrow oedema specificity is high but sensitivity only moderate $[15,16]$.

In the field of US and MRI, different working groups have developed standardized and reproducible assessment techniques. For MRI, a semi-quantitative scoring system (RA MRI scoring System, RAMRIS) and a core set of basic MRI sequences have been published [17]. In US, standards for modes of acquisition [18] and definitions of joint pathologies have been proposed [19].

The aim of the present cross-sectional study was to compare the accuracy of two new approaches using either lowfield MRI or combined US and ACPA with the American College of Rheumatology (ACR) 1987 classification criteria [20] in individuals with established RA. As gold standard references we used the historical fulfilment of the ACR 1987 criteria and RA diagnosed by a rheumatologist.

\section{Methods}

\section{Participants}

In 2004, a population-based, cross-sectional study of 4,995 randomly selected individuals was conducted in the southern part of Denmark with the aim of describing the point and cumulative prevalence of RA. On the basis of responses to a screening postal questionnaire, telephone interviews and data from local and nationwide registers, 73 individuals from the sample attended a clinical examination. At the examination individuals who had selfreported RA on the screening questionnaire by answering "yes" to the item "Have you or have you ever had RA" were invited to participate in the present study, which was conducted in 2005. Details about the algorithm for inviting individuals to the examination have previously been reported [21].

\section{Standard references}

No true gold standard definition of RA exists, and the most generally used in practice are fulfilment of the ACR 1987 classification criteria. In the present study, data from national and local registers, medical records and questionnaires were collected at hospitals and from general practitioners. All available materials were scrutinized to ascertain individuals in whom the historic fulfilment of the ACR 1987 criteria could be documented (classification) [21], and in the present study this was used as the primary standard reference. To obtain an alternative standard reference the disease status of the participants was evaluated by a rheumatologist (AV) who retrospectively was given access to the results of current investigations (except MRI, ACPA, and US) and documentation from hospitals and general practitioners. The rheumatologist then indicated if the participant had RA or specified an alternative diagnosis.

\section{Investigations}

During interviews, data on symptom duration, morning stiffness, current medications, the Medical Outcomes Study Short Form with 36 items (SF-36) [22] and Health Assessment Questionnaire-Disability Index (HAQ-DI) [23] were collected. Conventional radiography of wrists, hands (posterior-anterior projection) and feet (anterior-posterior projection) were evaluated for Larsen-score [24] by an experienced radiologist, blinded to all other information. According to this method a joint with score $\geq 2$ is erosive. Blood samples were examined for ACPA (EliA IgG, Phadia ImmunoCap, enzymelinked immunosorbent assay (ELISA), cut-off $\geq 10 \mathrm{AU} / \mathrm{l}$ ) [7,8], IgM rheumatoid factor (RF) (ELISA, cut-off $>8$ IE/ $\mathrm{ml}$ ), erythrocyte sedimentation rate (ESR, $\mathrm{mm} /$ hour), and $\mathrm{C}$-reactive protein (CRP, $\mathrm{mg} / \mathrm{l})$. In the individuals with RA, disease activity scores were calculated using 28 joints and CRP (DAS28) [25].

\section{Current 1987 ACR criteria}

On the day MRI and US were performed, the participants were examined for the presence of rheumatic nodules, 
swollen and tender joints (40 joints) by a rheumatologist, blinded to all other information. Fulfilment of the list format of the ACR 1987 criteria on the day of the examination ("current ACR 1987 criteria") was tested using the following parameters: joint stiffness ( $\geq 60$ minutes), rheumatic nodules, erosions on radiography (32 joints), RF, and patterns of clinical joint swelling (38 joints).

\section{US}

The participants were examined by US using a General Electric Logiq 9 BT03 ultrasound unit (General Electric, Solingen, Germany) with a $14 \mathrm{Mhz}$ linear active matrix probe with fixed GS and PD settings. US was performed by one of two rheumatologists (TL, LSA), blinded to all other information. Prior to the present study, the examiners performed an evaluation of inter-observer agreement in a pilot study. Based on the semi-quantitative scoring system described by Szkudlarek et al, GS synovitis was graded 0-4, US bone erosions 0-3, and PD synovitis $0-3$ in the metacarpophalangeal (MCP), metatarsophalangeal (MTP) and proximal interphalangeal (PIP) joints $[10,12,26]$. In these joints, scores $\geq 2$ were considered to represent definite pathologies. In the wrists, the same features were also evaluated, but only graded 0-1 ( 0 = absent, 1 = present). Only joints with GS synovitis score $\geq 1$ were examined by PD. The joints were examined in all accessible planes within 15-45 minutes.

\section{Adapted 1987 ACR criteria}

We defined the list format of the adapted ACR 1987 criteria using the following parameters: joint stiffness $(\geq 60$ minutes), rheumatic nodules, RF substituted with ACPA and clinical joint swelling and erosions on radiography with US synovitis and US erosions (32 joints).

\section{MRI}

On the day the participants were investigated by US, MRI of the non-dominant hand was performed using a 0.2 Tesla Artoscan MRI unit (Esaote Biomedica, Genoa, Italy). The investigation focused on the wrist but, if included in the field of view (FOV), MCP joints 2-5 were also evaluated. Coronal T1-weighted (T1) short tau inversion recovery (STIR) and T1 gradient echo (GE) three dimensional (3D) sequences were performed before and after intravenously injected gadodiamide $(0.1 \mathrm{mmol} / \mathrm{kg}$ body weight; Omniscan (Amersham Health, Norway)). The following imaging parameters were used: STIRimages: echo time (TE) $18 \mathrm{~ms}$, repetition time (TR) 1100 ms, gap 0.0, slice thickness $3.0 \mathrm{~mm}$, FOV $200 \times 200 \mathrm{~mm}$, matrix $256 \times 160$. T1-GE-3D images: TE $12 \mathrm{~ms}$, TR 30 ms, FOV $140 \times 140 \times 80 \mathrm{~mm}$, matrix $192 \times 160 \times 80$. The images were evaluated according to RAMRIS [17] by one experienced reader (BE) $[27,28]$. The RAMRIS scores were assessed for synovitis (possible range for wrist and
MCP joints 2-5: 0-21), bone oedema (0-69), bone erosion (0-230), and for the present study a composite score was calculated comprising all three joint pathologies.

\section{Statistics}

Comparisons between groups were made using $\chi^{2}$ for binary and Mann-Whitney U tests for continuous variables (level of significance: 0.05; two-sided). The accuracy was evaluated using sensitivity, specificity and Area under Curve (AUC) for Receiver Operating Characteristics (ROC) curves. For specific cut-offs on a scale the ROC-area was calculated as (sensitivity + specificity)/2. The AUC for ROC curves and the ROC-area estimate the correct classification of individuals by the index test. For the RAMRIS scales areas under ROC curves were compared using nonparametric statistics for correlated data [29]. The inter-observer agreement was evaluated using unweighted kappa statistics [30]. Statistics were calculated using Stata, version 8.2. (StatCorp, College Station, Texas).

\section{Ethics}

Informed consent was acquired from all participants and the study was approved by the local ethics committee (Den Regionale Videnskabsetiske Komité for Ringkjøbing, Ribe og Sønderjyllands Amt; reference no. 2426-02) and the Danish Data Protection Agency (reference no. 200241-2231).

\section{Results}

In the US study, 53 individuals were included; 20 historically fulfilled the ACR 1987 criteria (classification) and 18 were diagnosed as having RA (diagnosis). In three individuals MRI images were damaged during a flood and could not be recovered. In 50 individuals the unilateral wrist was investigated by MRI and in 31 the MCP joints were also included (Figure 1). One individual with RA (according to both standard references) had allergy and was examined by MRI without gadodiamide.

In the group without RA, the individuals were diagnosed with inflammatory and non-inflammatory conditions (Table 1).

The individuals who historically fulfilled the ACR 1987 criteria (classification) were significantly older, had higher swollen and tender joint counts, ESR and CRP than those who did not. They were also more often erosive on radiography, ACPA and RF positive, currently treated with DMARDs (monotherapy with methotrexate or sulfasalazine in 11, combination therapy in five individuals (including anti-tumor necrosis factor alpha therapy in four)), had higher HAQ-scores, GS synovitis and US erosive joint counts, RAMRIS erosion and oedema scores in the wrist and MCP joints, and synovitis scores in MCP joints. For symptom duration, SF-36 physical component scores, the fraction of females, the numbers of individuals with at 


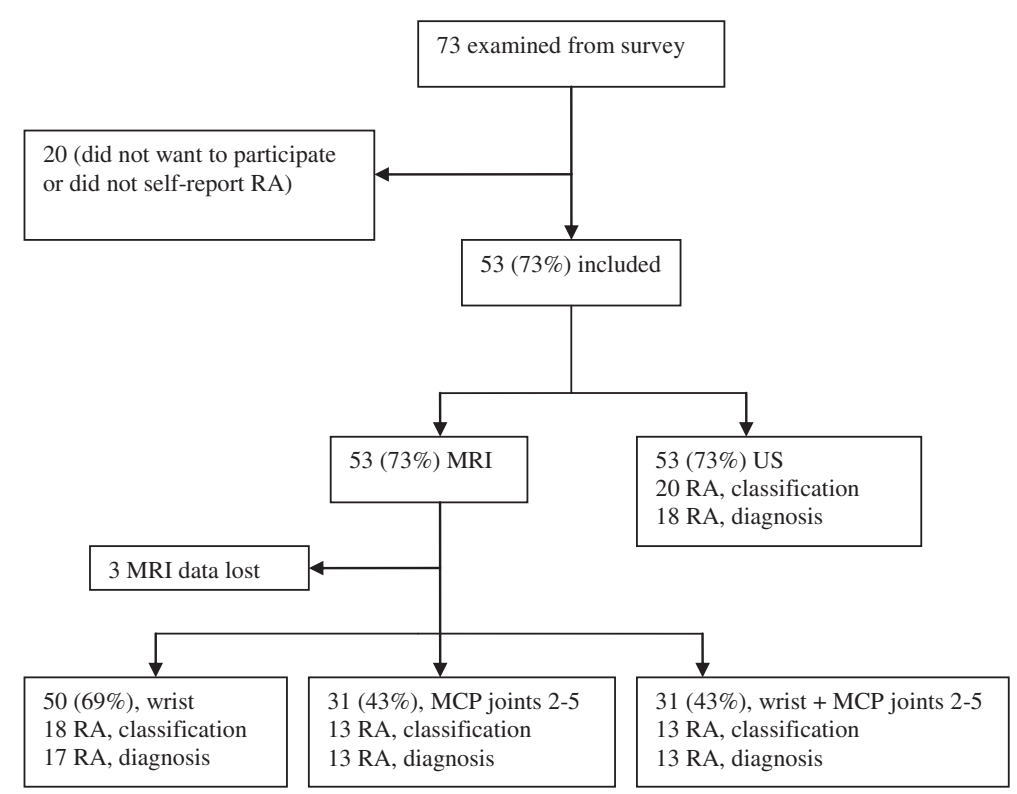

Figure 1 Numbers of participants in magnetic resonance imaging and ultrasonography analyses. Historic fulfilment of American College of Rheumatology (ACR) 1987 criteria (classification) or diagnosis with rheumatoid arthritis (RA) by rheumatologist (diagnosis). MCP, metacarpophalangeal. MRI, magnetic resonance imaging; US, ultrasonography.

least one joint with US erosions, and MRI synovitis scores in the wrist the two groups were not significantly different (Table 2). Four (20\%) of the individuals who fulfilled the ACR 1987 criteria had DAS28<2.6, 14 (70\%) had scores $\geq 3.2$, and none had scores $\geq 5.1$.

\section{Index test}

The sensitivity, specificity and ROC-area of the list format of the ACR 1987 ("current ACR 1987 criteria") were 50\%, $100 \%$ and $75 \%$ (classification) and $44 \%, 94 \%$ and $69 \%$ (diagnosis) (Table 3). For the list format of the adapted ACR 1987 criteria with GS synovitis, US erosions and ACPA, the sensitivity, specificity and ROC-area were $75 \%$, $97 \%$ and $86 \%$ (classification) and $72 \%, 91 \%$ and $82 \%$ (diagnosis). If GS synovitis and US erosions were combined

Table 1 Diagnosis by rheumatologist in the 53 participants

\begin{tabular}{ll}
\hline Diagnosis & Numbers (\%) \\
\hline Rheumatoid arthritis & $18(34)$ \\
Unspecified arthritis & $1(2)$ \\
Reactive arthritis & $3(6)$ \\
Psoriatic arthritis & $1(2)$ \\
Juvenile idiopathic arthritis & $1(2)$ \\
Arthralgia & $16(30)$ \\
Osteoarthritis & $9(17)$ \\
Low back pain & $1(2)$ \\
Gout & $1(2)$ \\
Haemochromatosis & $2(4)$ \\
\hline
\end{tabular}

with RF (instead of ACPA), the specificity was slightly lower. Combining GS synovitis, erosions on radiography (instead of US erosions) and ACPA, the sensitivity decreased with no increase in specificity. Using PD synovitis in the adapted ACR 1987 criteria, the specificity was 100\% but the sensitivity was lower than for the ACR 1987 criteria (Table 3).

Looking at MRI in the MCP joints at cut-off $\geq 5$ for synovitis, the sensitivity, specificity and ROC-area were $62 \%, 94 \%$ and $78 \%$ (classification) and 69\%, 100\% and $85 \%$ (diagnosis). For the wrist and MCP joints combined at cut-off $\geq 10$ for synovitis, the sensitivity, specificity and ROC-area were 62\%, 94\% and 78\% (same values for both classification and diagnosis) (Table 3). At no other cutoff for the RAMRIS scales in the wrist, MCP, or MCP and wrist joints combined was the ROC-area higher than for the ACR 1987 criteria (Figure 2).

In the wrist, MCP and wrist and MCP joints combined, the AUC for the composite scale was higher than the AUC for the other joint pathologies detected by MRI (Figure 2).

\section{Pilot study}

In the preceding pilot study, a total of 112 joints from four RA patients (seven wrists, 35 MCP, 35 PIP, 35 MTP joints) were evaluated by US. Overall, the kappa values for definite joint pathologies were 0.80 (95\% confidence interval (CI): 0.63-0.97) for GS synovitis, 0.75 (95\% CI: 0.56-0.94) for PD synovitis, and 0.84 (95\% CI: 0.73-0.97) for US erosions, corresponding to good or very good agreement. 
Table 2 Characteristics in $\mathbf{5 3}$ participants according to historic fulfilment of the American College of Rheumatology 1987 criteria

\begin{tabular}{|c|c|c|c|}
\hline & Rheumatoid arthritis $(n=20)$ & Not rheumatoid arthritis $(n=33)$ & P-value \\
\hline Female, n (\%) & $14(70)$ & $16(49)$ & .178 \\
\hline Age, years & $72(30-79)$ & $59(31-82)$ & .008 \\
\hline Symptom duration, years ${ }^{\S}$ & $15(2-32)$ & $11(1-53)$ & .369 \\
\hline Swollen joint count (40 joints) & $4.5(0-10)$ & $0(0-6)$ & .000 \\
\hline Tender joint count (40 joints) & $10(0-40)$ & $3(0-28)$ & .006 \\
\hline Current treatment with DMARDs, n (\%) & $16(80)$ & $0(0)$ & .000 \\
\hline $\mathrm{CRP}, \mathrm{mg} / \mathrm{l}$ & $5.5(0-33)$ & $3(1-14)$ & .050 \\
\hline ESR, mm/hour & $17(2-53)$ & $5(1-28)$ & .000 \\
\hline Positive RF (>8 IE/ml), n (\%) & $13(65)$ & $1(3)$ & .000 \\
\hline Positive ACPA ( $\geq 10 \mathrm{AU} / \mathrm{l}), \mathrm{n}(\%)$ & $12(60)$ & $0(0)$ & .000 \\
\hline Positive ACPA and RF, n (\%) & $11(55)$ & $0(0)$ & .000 \\
\hline SF-36, physical component score* & $38(21-60)$ & $40(16-57)$ & .441 \\
\hline $\mathrm{HAQ}-\left.\mathrm{D}\right|^{*}$ & $0.5(0-2.375)$ & $0.25(0-2.125)$ & .049 \\
\hline DAS28 & $3.7(1.8-5.0)$ & NR & NR \\
\hline Radiography, erosive (32 joints, $\geq 1$ joint with erosion), n (\%) & $12(60)$ & $2(6)$ & .000 \\
\hline Radiography, Larsen score & $21.5(0-80)$ & $0(0-13)$ & .000 \\
\hline RAMRIS, erosion score (wrist) $)^{\#}$ & $4(0-125)$ & $1(0-6)$ & .001 \\
\hline RAMRIS, erosion score (MCP-joints 2-5) ${ }^{\dagger}$ & $1(0-8)$ & $0(0-4)$ & .009 \\
\hline RAMRIS, bone marrow oedema score (wrist) & $2(0-18)$ & $0(0-9)$ & .002 \\
\hline RAMRIS, bone marrow oedema score (MCP joints $2-5)^{+}$ & $0(0-5)$ & $0(0-2)$ & .025 \\
\hline RAMRIS, synovitis score (wrist) ${ }^{\#}$ & $4(1-9)$ & $3(1-6)$ & .119 \\
\hline RAMRIS, synovitis score (MCP joints $2-5)^{\dagger}$ & $6(1-8)$ & $3(0-6)$ & .017 \\
\hline GS synovitis joint count (30 joints, score $\geq 2$ ) & $4.5(0-19)$ & $0(0-6)$ & .000 \\
\hline GS synovitis joint count (wrists) & $1(0-2)$ & $0(0-1)$ & .001 \\
\hline PD joint count (30 joints; score $\geq 2$ ) & $1(0-14)$ & $0(0-2)$ & .000 \\
\hline PD joint count (wrists) & $0(0-2)$ & $0(0-1)$ & .001 \\
\hline US erosive joint count ( 30 joints, score $\geq 2$ ) & $10.5(0-23)$ & $1(0-10)$ & .000 \\
\hline US erosive joint count (wrists) & $0.5(0-2)$ & $0(0-1)$ & .000 \\
\hline US erosive ( 32 joints; $\geq 1$ joint with erosion), $n$ (\%) & $19(95)$ & $31(94)$ & .871 \\
\hline
\end{tabular}

Values are median (range), unless otherwise stated. Mann-Whitney $U$ test for continuous variables; $\chi^{2}$ test for proportions. $\S R$ heumatoid arthritis, $n=19 ;$ not rheumatoid arthritis, $n=32$. *Not rheumatoid arthritis, $n=32$. "Rheumatoid arthritis, $n=18$, not rheumatoid arthritis $n=32$. ${ }^{\dagger}$ Rheumatoid arthritis, $n=13$; not rheumatoid arthritis, $n=18$. ACPA, anti-cyclic citrullinated peptide antibody; CRP, C-reactive protein; DAS28, disease activity score in 28 joints using CRP; DMARDs, disease-modifying antirheumatic drugs; ESR, erythrocyte sedimentation rate; GS, grey-scale; HAQ-DI, Health Assessment Questionnaire-Disability Index; MCP, metacarpophalangeal; NR, not relevant; PD, Power Doppler; RAMRIS, Rheumatoid Arthritis Magnetic Resonance Imaging scoring System; RF, IgM rheumatoid factor; SF-36, Medical Outcomes Study Short Form (36 items); US, ultrasonography.

\section{Discussion}

The main finding of our study was that the correct classification of individuals with established RA was improved with two new approaches using low-field MRI or combined US and ACPA. Compared with the ACR 1987 criteria ("current ACR 1987 criteria"), the ROC-area increased from $75 \%$ to $86 \%$ using the adapted ACR 1987 criteria (with US synovitis, US erosions, and ACPA) with the historic fulfilment of the ACR 1987 criteria (classification) as standard reference. Looking solely on MRI synovitis in the MCP joints or wrist and MCP joints combined, the ROC-area increased to $78 \%$ (i.e. without incorporating information from clinical, biochemical or other imaging parameters). Although many of the individuals with RA were currently treated with DMARDs, the sensitivity and specificity of the adapted ACR 1987 criteria was close to the accuracy of the ACR 1987 criteria in a recent meta-analysis (sensitivity $79-80 \%$, specificity $90-93 \%$ ) [31].

In the US pilot study, the inter-observer agreement for definite joint pathologies was high. Originally Szkudlarek et al did not include the wrist in their scoring system $[10,12,26]$, but today we could have used a more detailed scale for synovitis in the wrist [32]. Moreover, if all the 
Table 3 Sensitivity, specificity and area under Receiver Operating Characteristics curve (ROC-area) of index test

\begin{tabular}{|c|c|c|c|c|c|c|}
\hline & \multicolumn{6}{|c|}{ Standard references } \\
\hline & \multicolumn{3}{|c|}{ Historic fulfilment of ACR 1987 criteria } & \multicolumn{3}{|c|}{ Diagnosis by rheumatologist } \\
\hline & Sensitivity & Specificity & ROC-area & Sensitivity & Specificity & ROC-area \\
\hline \multicolumn{7}{|l|}{ ACR 1987 criteria } \\
\hline & $50(27-73)$ & $100(89-100)$ & $75(64-86)$ & $44(22-69)$ & $94(81-99)$ & $69(57-82)$ \\
\hline \multicolumn{7}{|l|}{$\begin{array}{l}\text { Adapted ACR } 1987 \text { criteria } \\
\text { (GS synovitis, US erosions, ACPA) }\end{array}$} \\
\hline & $75(51-91)$ & $97(84-100)$ & $86(76-96)$ & $72(47-90)$ & $91(77-98)$ & $82(70-93)$ \\
\hline \multicolumn{7}{|l|}{$\begin{array}{l}\text { Adapted ACR } 1987 \text { criteria } \\
\text { (GS synovitis, US erosions, RF) }\end{array}$} \\
\hline & $75(51-91)$ & $94(80-99)$ & $84(74-95)$ & $72(47-90)$ & $87(73-97)$ & $80(68-92)$ \\
\hline \multicolumn{7}{|l|}{$\begin{array}{l}\text { Adapted ACR } 1987 \text { criteria } \\
\text { (GS synovitis, erosions on radiography, ACPA) }\end{array}$} \\
\hline & $60(36-81)$ & $97(84-100)$ & $79(67-91)$ & $56(31-79)$ & $91(77-98)$ & $73(61-86)$ \\
\hline \multicolumn{7}{|l|}{$\begin{array}{l}\text { Adapted ACR } 1987 \text { criteria } \\
\text { (PD synovitis, US erosions, ACPA) }\end{array}$} \\
\hline & $35(15-59)$ & $100(89-100)$ & $67(57-78)$ & $39(17-64)$ & $100(90-100)$ & $69(58-81)$ \\
\hline \multicolumn{7}{|l|}{ RAMRIS scale for synovitis } \\
\hline MCP joints 2-5 (cut-off $\geq 5$ ) & $62(32-86)$ & $94(73-100)$ & $78(63-93)$ & $69(39-91)$ & $100(73-100)$ & $85(72-98)$ \\
\hline Combined wrist and MCP joints $2-5$ (cut-off $\geq 10$ ) & $62(32-86)$ & $94(73-100)$ & $78(63-93)$ & $62(32-86)$ & $94(73-100)$ & $78(63-93)$ \\
\hline
\end{tabular}

Historic fulfilment of the American College of Rheumatology (ACR) 1987 criteria (classification) or diagnosis with rheumatoid arthritis by rheumatologist (diagnosis) as standard reference, \% (95\% confidence interval). ACPA, anti-cyclic citrullinated peptide antibody; GS, grey-scale; MCP, metacarpophalangeal; PD, Power Doppler; RAMRIS, Rheumatoid Arthritis Magnetic Resonance Imaging scoring System; RF, IgM rheumatoid factor; US, ultrasonography.

joints had been examined for PD synovitis, the sensitivity of the adapted ACR 1987 criteria using PD synovitis might have been higher.

The numbers of participants with at least one joint with US erosions was equally high among those who were classified as having RA and those who were not. In previous studies erosions have often been detected in healthy individuals [33] and individuals with arthritides as diagnosed in our study [34-36].

To our knowledge, the accuracy of an approach including US as a criterion for the classification of individuals with RA in a cross-sectional design has not previously been systematically evaluated.

As a single test for RA, ACPA and RF have equal sensitivity but ACPA has higher specificity [37]. In two previous, cross-sectional studies in hospital patients, substituting rheumatic nodules and erosions on radiography with ACPA, the sensitivity of the ACR 1987 criteria increased with a decrease in specificity [38,39]. Adding ACPA as a criterion to the ACR 1987 criteria, the sensitivity improved with little loss in specificity [39]. In our study, most of the individuals with RA were both ACPA and RF positive and the majority of those without RA where ACPA and RF negative. This explains why the accuracy of the adapted ACR 1987 criteria changed only slightly when ACPA was used instead of RF.

Turning to MRI, with the diagnosis as standard reference the ROC-area (cut-off $>5$ ) on the RAMRIS scale for synovitis in the MCP joints was $85 \%$. Most of the individuals with RA had moderate disease activity and were treated with methotrexate or sulfasalazine as monotherapy and our results confirm that with MRI it is possible to detect subclinical synovitis [40]. On the other hand, using a low-field MRI unit and examining one individual with RA without contrast agent we probably underestimated the occurrence of bone marrow oedema $[15,16]$ and synovitis [41]. The non-dominant hand was examined by MRI but based on previous reports [42,43], we do not think that this has biased our results.

The AUC for the ROC curves of the composite scale comprising all three joint pathologies defined by RAMRIS was highest in every joint area, indicating that both damage and inflammation contributed with relevant information for the correct classification of the individuals. RA is a polyarticular disease and if more joint areas had been investigated the AUC of the composite scale might have been higher. However, the inclusion of more joint areas will increase the acquisition time and using RAMRIS guidelines requires that contrast medium is administered repeatedly and this would make low-field MRI less patient-friendly. In a previous cross-sectional study of consecutive outpatients diagnosed with RA and healthy individuals, low-field MRI of the bilateral wrist and MCP joints 2-5 was evaluated using a modified version of RAMRIS without contrast agent. The sensitivity and specificity were $65 \%$ and $83 \%$ for bone oedema (the cut-off was not 


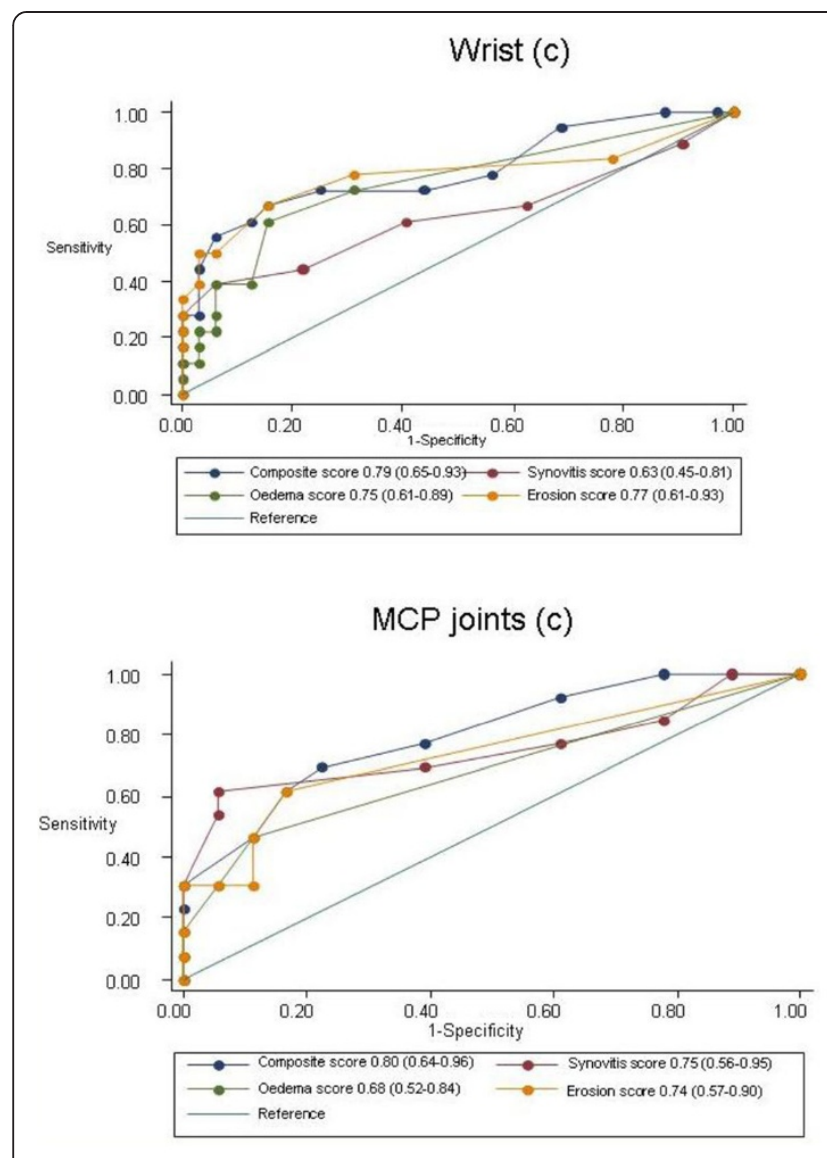

Wrist and MCP joints (c)

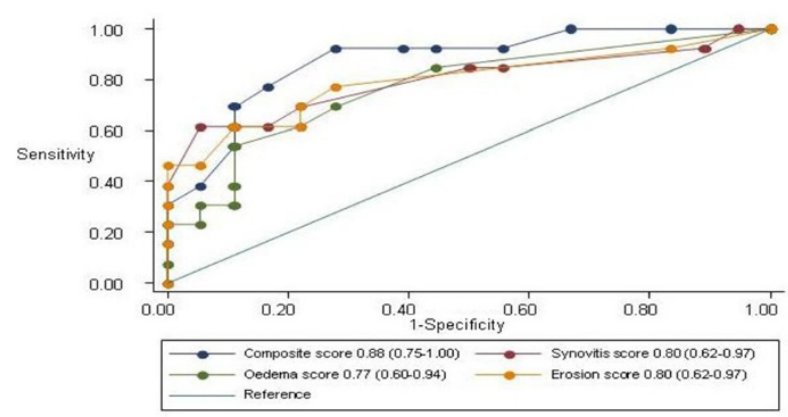

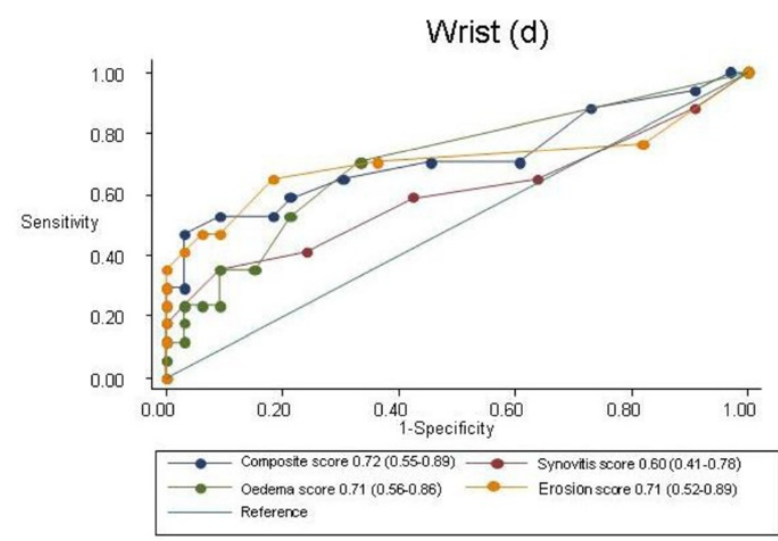



Wrist and MCP joints (d)

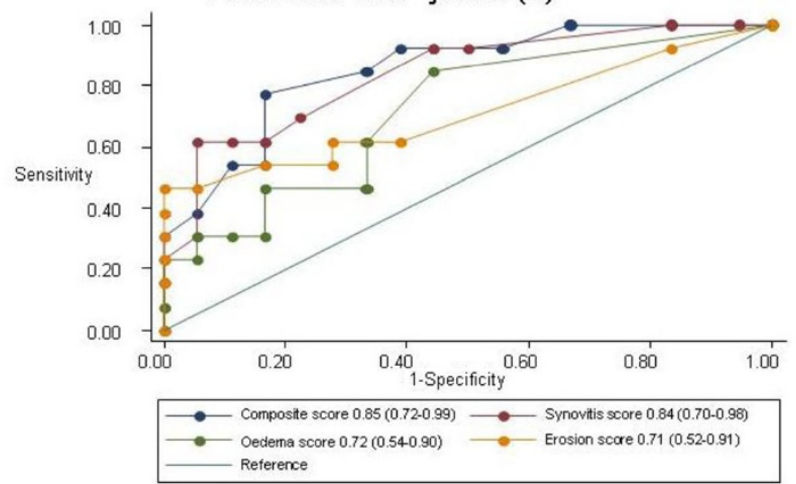

Figure 2 Areas under Receiver Operating Characteristics curves for Rheumatoid Arthritis Magnetic Resonance Imaging scoring System. Bone oedema, bone erosion, synovitis and composite scales in unilateral wrist and metacarpophalangeal (MCP) joints 2-5 with historic fulfilment of American College of Rheumatology 1987 criteria (classification, c) or diagnosis with rheumatoid arthritis by rheumatologist (diagnosis, d) as standard references ( $95 \%$ confidence interval).

clearly stated), $70 \%$ and $80 \%$ for synovitis (score $>2$ ) and $55 \%$ and $90 \%$ for erosions ( $>5$ erosions) [43].

Our study was conducted in 2005 with the ACR 1987 criteria to test. Recently, new classification criteria for RA have been introduced (2010 ACR/European League Against Rheumatism (EULAR) criteria) for the early identification of individuals with arthritis at high risk of developing erosive or persistent disease [44]. The participants did not all have at least one swollen joint at the clinical examination, which is the eligibility criterion for testing with the 2010 ACR/EULAR criteria. Consequently, we did not perform post hoc analyses with the new criteria. Neither did we use previously described criteria for the ascertainment of individuals with RA in twin studies [45].

However, after the introduction of the new criteria for RA it seems that a fraction may only fulfil the ACR 1987 
criteria [46]. Individuals who fulfil the new criteria may often achieve drug free remission [47] and it is not clear if the new criteria may be applied meaningfully in a retrospective or cumulative way [48]. It therefore still seems relevant to estimate the incidence and prevalence of RA using the 1987 ACR criteria, until more descriptive data with the $2010 \mathrm{ACR} / \mathrm{EULAR}$ criteria have been published.

The main weakness of the present study is that the low numbers of participants resulted in rather wide and overlapping confidence intervals for the point estimates of accuracy. Nevertheless, the participants were recruited from a random sample of the general population and we think that the approaches described here may be used in future epidemiological studies conducted with the aim of estimating the prevalence of RA in a selected population.

In our opinion, the high fraction of individuals with non-inflammatory conditions after the diagnostic workup reflects the general methodological problem that in population based studies aiming to describe the prevalence of RA, it is difficult to identify individuals at high risk of having RA [21]. Many of the participants in our study had actually been seen in ambulatory settings and our results may also apply to a hospital outpatient population. However, since the accuracy of an index test may change with the disease severity among the cases and the spectrum of diseases among the non-cases [49], this assumption should be tested in a consecutive series of outpatients.

\section{Conclusions}

In this cross-sectional study the correct classification of individuals with established RA was improved over what was seen for the ACR 1987 criteria by two new approaches either using low-field MRI or a combination of US and ACPA. Our results may apply to cross-sectional epidemiological studies conducted with the aim of estimating the prevalence of RA. Whether they also apply for patients in ambulatory settings has to be confirmed.

\section{Support}

The contrast agent was sponsored by Amersham Health, Norway. The study was funded by the Region of Southern Denmark (formerly the County of South Jutland), Denmark; the Danish Rheumatism Association; the Margarethe Astrid Hedvig Schaufuss Grant; Grocer Hans Christensen's Memorial Grant. The work by $\mathrm{AV}$ was sponsored by an individual grant from the Danish Rheumatism Association (R33-A1836) and the AP Møller Foundation.

\section{Abbreviations}

ACPA: Anti-cyclic citrullinated peptide antibody; ACR: American College of Rheumatology; AUC: Area under curve; CRP: C-reactive protein; DAS28: Disease activity score in 28 joints using CRP; DMARDs: Disease-modifying antirheumatic drugs; ELISA: Enzyme-linked immunosorbent assay; ESR: Erythrocyte sedimentation rate; EULAR: European League Against Rheumatism; FOV: Field of view; GE: Gradient echo; GS: Grey-scale; HAQ-DI: Health Assessment
Questionnaire-Disability Index; MCP: Metacarpophalangeal; MRI: Magnetic resonance imaging; MTP: Metatarsophalangeal; NR: Not relevant; PD: Power Doppler; PIP: Proximal interphalangeal; RA: Rheumatoid arthritis; RAMRIS: Rheumatoid Arthritis Magnetic Resonance Imaging scoring System; RF: IgM rheumatoid factor; ROC: Receiver Operating Characteristics; SF-36: Medical Outcomes Study Short Form; STIR: Short-tau inversion recovery; TE: Echo time; TR: Repetition time; T1: T1-weighted; US: Ultrasonography; 3D: Three dimensional.

\section{Competing interests}

JKP, BE, MS, AV, MØ, AJS, LSA, KHP: None declared. TL: Advisory Board member, Roche and Pfizer.

\section{Authors' contributions}

Conception and design of study: JKP, TL, MS, MØ, AJS, KHP, LSA. Acquisition of data: JKP, TL, BE, AV, LSA, KHP. Data analysis: JKP, TL. Drafting of manuscript: JKP. Interpretation of data, and revision of manuscript: all authors. All authors read and approved the final manuscript.

\section{Acknowledgements}

We would like to thank research secretary Kirsten Frøhlich and research nurses Jannie M. Frederiksen and Pia Rasmussen for data collection and Steen Nielsen (MD), Department of Radiology, Sønderborg, Hospital of Southern Jutland, for the evaluation of radiography.

\section{Author details}

${ }^{1}$ King Christian 10th Hospital for Rheumatic Diseases, South Jutland Hospital, Toldbodgade 3, 6300 Graasten, Denmark. ²Department of Rheumatology, Odense University Hospital, Odense, Denmark. ${ }^{3}$ Department of Rheumatology, Regional Hospital Slagelse, Slagelse, Denmark. ${ }^{4}$ Department of Rheumatology, University of Copenhagen Hospital at Køge, Køge, Denmark. ${ }^{5}$ Copenhagen Center for Arthritis Research, Center for Rheumatology and Spinal Diseases, Glostrup Hospital, Glostrup, Denmark. ${ }^{6}$ Department of Clinical Medicine, Faculty of Health and Medical Sciences, University of Copenhagen, Copenhagen, Denmark. ${ }^{7}$ Epidemiology, Institute of Public Health, University of Southern Denmark, Odense, Denmark. ${ }^{8}$ Institute of Regional Health Services Research, University of Southern Denmark, Odense, Denmark.

Received: 13 September 2013 Accepted: 28 July 2014

Published: 7 August 2014

\section{References}

1. Smolen JS, Landewé R, Breedveld FC, Dougados M, Emery P, Gaujoux-Viala C, Gorter S, Knevel R, Nam J, Schoels M, Aletaha D, Buch M, Gossec L, Huizinga T, Bijlsma JW, Burmester G, Combe B, Cutolo M, Gabay C, GomezReino J, Kouloumas M, Kvien TK, Martin-Mola E, McInnes I, Pavelka K, van Riel P, Scholte M, Scott DL, Sokka T, Valesini G, et al: EULAR recommendations for the management of rheumatoid arthritis with synthetic and biological disease-modyfying antirheumatic drugs. Ann Rheum Dis 2010, 69:964-975.

2. Pincus T, Sokka T, Kautiainen H: Patients seen for standard rheumatoid arthritis care have significantly better articular, radiographic, laboratory, and functional status in 2000 than in 1985. Arthritis Rheum 2005, 52:1009-1019

3. Welsing PM, Fransen J, van Riel PL: Is the disease course of rheumatoid arthritis becoming milder? Time trends since 1985 in an inception cohort of early rheumatoid arthritis. Arthritis Rheum 2005, 52:2616-2624.

4. Weiss RJ, Stark A, Wick MC, Ehlin A, Palmblad K, Wretenberg P: Orthopaedic surgery of the lower limbs in 49,802 rheumatoid arthritis patients: results from the Swedish National Inpatient Registry during 1987 to 2001. Ann Rheum Dis 2006, 65:335-341.

5. Weiss RJ, Ehlin A, Montgomery SM, Wick MC, Stark A, Wretenberg P: Decrease of RA-related orthopaedic surgery of the upper limbs between 1998 and 2004: data from 54,579 Swedish RA inpatients. Rheumatology (Oxford) 2008, 47:491-494.

6. Shourt CA, Crowson CS, Gabriel SE, Matteson EL: Orthopedic surgery among patients with rheumatoid arthritis 1980-2007: a population-based study focused on surgery rates, sex, and mortality. J Rheumatol 2012, 39:481-485.

7. Dejaco C, Klotz W, Larcher H, Duftner C, Schirmer M, Herold M: Diagnostic value of antibodies against a modified citrullinated vimentin in rheumatoid arthritis. Arthritis Res Ther 2006, 8:R119. 
8. Coenen D, Verschueren P, Westhovens R, Bossuyt X: Technical and diagnostic performance of 6 assays for the measurement of citrullinated protein/peptide antibodies in the diagnosis of rheumatoid arthritis. Clin Chem 2007, 53:498-504.

9. Wakefield RJ, Green MJ, Marzo-Ortega H, Conaghan PG, Gibbon WW, McGonagle D, Proudman S, Emery P: Should oligoarthritis be reclassified? Ultrasound reveals a high prevalence of subclinical disease. Ann Rheum Dis 2004, 63:382-385.

10. Szkudlarek M, Klarlund M, Narvestad E, Court-Payen M, Strandberg C, Jensen KE, Thomsen HS, Østergaard M: Ultrasonography of the metacarpophalangeal and proximal interphalangeal joints in rheumatoid arthritis: a comparison with magnetic resonance imaging, conventional radiography and clinical examination. Arthritis Res Ther 2006, 8:R52.

11. Wakefield RJ, Gibbon WW, Conaghan PG, O'Connor P, McGonagle D, Pease C, Green MJ, Veale DJ, Isaacs JD, Emery P: The value of sonography in the detection of bone erosions in patients with rheumatoid arthritis: a comparison with conventional radiography. Arthritis Rheum 2000, 43:2762-2770.

12. Szkudlarek $M$, Court-Payen $M$, Strandberg $C$, Klarlund M, Klausen $T$, Ostergaard M: Power Doppler ultrasonography for assessment of synovitis in the metacarpophalangeal joints of patients with rheumatoid arthritis: a comparison with dynamic magnetic resonance imaging. Arthritis Rheum 2001, 44:2018-2023.

13. Terslev L, Torp-Pedersen S, Savnik A, von der Recke P, Qvistgaard E, Danneskiold-Samsøe B, Bliddal H: Doppler ultrasound and magnetic resonance imaging of synovial inflammation of the hand in rheumatoid arthritis: a comparative study. Arthritis Rheum 2003, 48:2434-2441.

14. Duer-Jensen A, Vestergaard A, Døhn UM, Ejbjerg B, Hetland ML, Albrecht-Beste $E_{1}$ Østergaard M: Detection of rheumatoid arthritis bone erosions by two different dedicated extremity MRI units and conventional radiography. Ann Rheum Dis 2008, 67:998-1003.

15. Ejbjerg BJ, Narvestad E, Jacobsen S, Thomsen HS, Østergaard M: Optimised, low cost, low field dedicated extremity MRI is highly specific and sensitive for synovitis and bone erosions in rheumatoid arthritis wrist and finger joints: comparison with conventional high field MRI and radiography. Ann Rheum Dis 2005, 64:1280-1287.

16. Savnik A, Malmskov H, Thomsen HS, Bretlau T, Graff LB, Nielsen $H$, Danneskiold-Samsøe B, Boesen J, Bliddal H: MRI of the arthritic small joints: comparison of extremity MRI (0.2 T) vs high-field MRI (1.5 T). Eur Radiol 2001, 11:1030-1038.

17. Østergaard M, Peterfy C, Conaghan P, McQueen F, Bird P, Ejbjerg B, Shnier R, O'Connor P, Klarlund M, Emery P, Genant H, Lassere M, Edmonds J: OMERACT Rheumatoid Arthritis Magnetic Resonance Imaging Studies. Core set of MRI acquisitions, joint pathology definitions, and the OMERACT RA-MRI scoring system. J Rheumatol 2003, 30:1385-1386.

18. Backhaus M, Burmester GR, Gerber T, Grassi W, Machold KP, Swen WA, Wakefield RJ, Manger B, Working Group for Musculoskeletal Ultrasound in the EULAR Standing Committee on International Clinical Studies including Therapeutic Trials: Guidelines for musculoskeletal ultrasound in rheumatology. Ann Rheum Dis 2001, 60:641-649.

19. Wakefield RJ, Balint PV, Szkudlarek M, Filippucci E, Backhaus M, D'Agostino MA, Sanchez EN, lagnocco A, Schmidt WA, Bruyn GA, Kane D, O'Connor PJ, Manger B, Joshua F, Koski J, Grassi W, Lassere MN, Swen N, Kainberger F, Klauser A, Ostergaard M, Brown AK, Machold KP, Conaghan PG, OMERACT 7 Special Interest Group: Musculoskeletal ultrasound including definitions for ultrasonographic pathology. J Rheumato/ 2005, 32:2485-2487.

20. Arnett FC, Edworthy SM, Bloch DA, McShane DJ, Fries JF, Cooper NS, Healey LA, Kaplan SR, Liang MH, Luthra HS, Medsger TA, Mitchell DM, Neustadt DH, Pinals RS, Schaller JG, Sharp JT, Wilder RL, Hunder GG: The American Rheumatism Association 1987 revised criteria for the classification of rheumatoid arthritis. Arthritis Rheum 1988, 31:315-324.

21. Pedersen JK, Svendsen AJ, Hørslev-Petersen K: Prevalence of rheumatoid arthritis in the southern part of Denmark. Open Rheumatol J 2011, 5:91-97.

22. Bjorner JB, Thunedborg K, Kristensen TS, Modvig J, Bech P: The Danish SF-36 Health Survey: translation and preliminary validity studies. $J$ Clin Epidemiol 1998, 51:991-999.

23. Thorsen H, Hansen TM, McKenna SP, Sørensen SF, Whalley D: Adaptation into Danish of the Stanford Health Assessment Questionnaire (HAQ) and the Rheumatoid Arthritis Quality of Life Scale (RAQoL). Scand J Rheumatol 2001, 30:103-109.
24. Larsen A, Dale K, Eek M: Radiographic evaluation of rheumatoid arthritis and related conditions by standard reference films. Acta Radiol Diagn (Stockh) 1977, 18:481-491.

25. Prevoo ML, van $t^{\prime} H$ of $M A$, Kuper $H H$, van Leuwen $M A$, van de Putte $L B$, van Riel PL: Modified disease activity scores that include twenty-eight-joints counts. Development and validation in a prospective longitudinal study of patients with rheumatoid arthritis. Arthritis Rheum 1995, 38:44-48.

26. Szkudlarek M, Court-Payen M, Jacobsen S, Klarlund M, Thomsen HS, Østergaard M: Interobserver agreement in ultrasonography of the finger and toe joints in rheumatoid arthritis. Arthritis Rheum 2003, 48:955-962.

27. Ejbjerg BJ, Vestergaard A, Jacobsen S, Thomsen HS, Østergaard M: The smallest detectable difference and sensitivity to change of magnetic resonance imaging and radiographic scoring of structural joint damage in rheumatoid arthritis finger, wrist, and toe joints: a comparison of the OMERACT rheumatoid arthritis magnetic resonance imaging score applied to different joint combinations and the Sharp/van der Heijde radiographic score. Arthritis Rheum 2005, 52:2300-2306.

28. Haavardsholm EA, Ostergaard M, Ejbjerg BJ, Kvan NP, Uhlig TA, Lilleås FG, Kvien TK: Reliability and sensitivity to change of the OMERACT rheumatoid arthritis magnetic resonance imaging score in a multireader, longitudinal setting. Arthritis Rheum 2005, 52:3860-3867.

29. DeLong ER, DeLong DM, Clarke-Pearson DL: Comparing the areas under two or more correlated receiver operating characteristic curves: a nonparametric approach. Biometrics 1988, 44:837-845.

30. Altman DG: Practical statistics for medical research. London: Chapman and Hall; 1991

31. Banal F, Dougados M, Combescure C, Gossec L: Sensitivity and specificity of the American College of Rheumatology 1987 criteria for the diagnosis of rheumatoid arthritis according to disease duration: a systematic literature review and meta-analysis. Ann Rheum Dis 2009, 68:1184-1191.

32. Dougados M, Jousse-Joulin S, Mistretta F, D'Agostino MA, Backhaus M, Bentin J, Chalès G, Chary-Valckenaere I, Conaghan P, Etchepare F, Gaudin P, Grassi W, van der Heijde D, Sellam J, Naredo E, Szkudlarek M, Wakefield R, Saraux A: Evaluation of several ultrasonography scoring systems for synovitis and comparison to clinical examination: results from a prospective multicentre study of rheumatoid arthritis. Ann Rheum Dis 2010, 69:828-833.

33. Millot F, Clavel G, Etchepare F, Gandjbakhch F, Grados F, Saraux A, Rat AC, Fautrel B, Bourgeois P, Fardellone P, Investigators of the French Early Arthritis Cohort ESPOIR: Musculoskeletal ultrasonography in healthy subjects and ultrasound criteria for early arthritis (the ESPOIR cohort). J Rheumatol 2011, 38:613-620.

34. Thiele RG, Schlesinger N: Diagnosis of gout by ultrasound. Rheumatology (Oxford) 2007, 46:1116-1121.

35. Wittoek R, Carron P, Verbruggen G: Structural and inflammatory sonographic findings in erosive and non-erosive osteoarthritis of the interphalangeal finger joints. Ann Rheum Dis 2010, 69:2173-2176.

36. Guggenbuhl $P$, Brissot $P$, Loréal $O$ : Miscellaneous non-inflammatory musculoskeletal conditions. Haemochromatosis: the bone and the joint. Best Pract Res Clin Rheumatol 2011, 25:649-664.

37. Nishimura K, Sugiyama D, Kogata Y, Tsuji G, Nakazawa T, Kawano S, Saigo K, Morinobu A, Koshiba M, Kuntz KM, Kamae I, Kumagai S: Meta-analysis: diagnostic accuracy of anti-cyclic citrullinated peptide antibody and rheumatoid factor for rheumatoid arthritis. Ann Intern Med 2007, 146:797-808.

38. Liao KP, Batra KL, Chibnik L, Schur PH, Costenbader KH: Anti-cyclic citrullinated peptide revised criteria for the classification of rheumatoid arthritis. Ann Rheum Dis 2008, 67:1557-1561.

39. Zhao J, Liu X, Wang Z, Li Z: Significance of anti-CCP antibodies in modification of 1987 ACR classification criteria in diagnosis of rheumatoid arthritis. Clin Rheumatol 2010, 29:33-38.

40. Brown AK, Conaghan PG, Karim Z, Quinn MA, Ikeda K, Peterfy CG, Hensor E, Wakefield RJ, O'Conner PJ, Emery P: An explanation for the apparent dissociation between remission and continued structural deterioration in rheumatoid arthritis. Arthritis Rheum 2008, 58:2958-2967.

41. Ostergaard M, Conaghan PG, O'Connor P, Szkudlarek M, Klarlund M, Emery P, Peterfy C, Genant H, McQueen FM, Bird P, Lassere M, Ejbjerg B: Reducing invasiveness, duration, and cost of magnetic resonance imaging in rheumatoid arthritis by omitting intravenous contrast injection - Does it change the assessment of inflammatory and destructive joint changes by the OMERACT RAMRIS? J Rheumato/ 2009, 36:1806-1810. 
42. Ostergaard M, Møller Døhn U, Duer-Jensen A, Hetland ML, Hørslev-Petersen K Stengaard-Pedersen K, Junker P, Pødenphant J, Ejbjerg B: Patterns of magnetic resonance imaging bone erosion in rheumatoid arthritis-which bones are most frequently involved and show the most change? J Rheumatol 2011, 38:2014-2017.

43. Olech E, Crues JV 3rd, Yocum DE, Merrill JT: Bone marrow edema is the most specific finding for rheumatoid arthritis (RA) on noncontrast magnetic resonance imaging of the hands and wrists: a comparison of patients with RA and healthy controls. J Rheumatol 2010, 37:265-274.

44. Aletaha D, Neogi T, Silman AJ, Funovits J, Felson DT, Bingham CO 3rd, Birnbaum NS, Burmester GR, Bykerk VP, Cohen MD, Combe B, Costenbader KH, Dougados M, Emery P, Ferraccioli G, Hazes JM, Hobbs K, Huizinga TW, Kavanaugh A, Kay J, Kvien TK, Laing T, Mease P, Ménard HA, Moreland LW, Naden RL, Pincus T, Smolen JS, Stanislawska-Biernat E, Symmons D, et al: 2010 rheumatoid arthritis classification criteria: an American College of Rheumatology/European League Against Rheumatism collaborative initiative. Ann Rheum Dis 2010, 69:1580-1588.

45. MacGregor AJ, Bamber S, Silman AJ: A comparison of the performance of different methods of disease classification for rheumatoid arthritis. Results of an analysis from a nationwide twin study. J Rheumatol 1994, 21:1420-1426.

46. Humphreys JH, Verstappen SM, Hyrich KL, Chipping JR, Marshall T, Symmons DP: The incidence of rheumatoid arthritis in the UK: comparisons using the 2010 ACR/EULAR classification criteria and the 1987 ACR classification criteria. Results from the Norfolk Arthritis Register. Ann Rheum Dis 2013, 72:1315-1320.

47. Krabben A, Huizinga TW, van der Helm-van Mil AH: Undifferentiated arthritis characteristics and outcomes when applying the 2010 and 1987 criteria for rheumatoid arthritis. Ann Rheum Dis 2012, 71:238-241.

48. Humphreys JH, Symmons DP: Postpublication validation of the 2010 American College of Rheumatology/European League Against Rheumatism classification criteria for rheumatoid arthritis: where do we stand? Curr Opin Rheumatol 2013, 25:157-163.

49. Guyatt G, Sackett D, Haynes B: Evaluating medical tests. In Clinical epidemiology. How to do clinical practice research. 3rd edition. Edited by Haynes RB, Sackett DL, Guyatt GH, Tugwell P. Philadelphia: Lippincott, Williams and Wilkins; 2006:273-322.

doi:10.1186/1471-2474-15-268

Cite this article as: Pedersen et al:: Low-field magnetic resonance imaging or combined ultrasonography and anti-cyclic citrullinated peptide antibody improve correct classification of individuals as established rheumatoid arthritis: results of a population-based, cross-sectional study. BMC Musculoskeletal Disorders 2014 15:268.

\section{Submit your next manuscript to BioMed Central and take full advantage of:}

- Convenient online submission

- Thorough peer review

- No space constraints or color figure charges

- Immediate publication on acceptance

- Inclusion in PubMed, CAS, Scopus and Google Scholar

- Research which is freely available for redistribution 